\title{
RESENAS
}

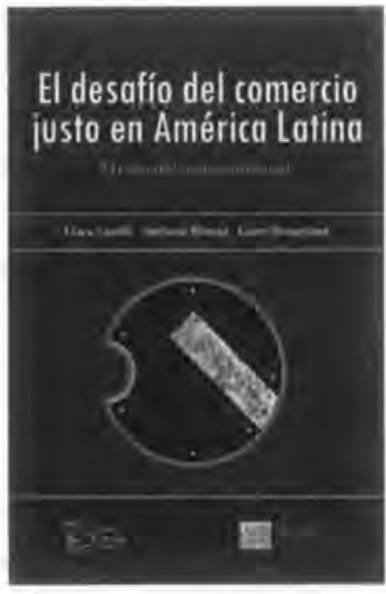

Clara Caselli, Stefania Mittiga y Laure Jongejans. El desafio del comercio justo en América Latina. El caso del sector artesanal. Lima: Fondo Editorial de la Universidad Católica Sedes Sapientiae/ Facoltà di Economia della Università degli Studi di Genova, 2006. 212 pp.

Desde siempre, el tema del comercio internacional suscita interrogantes éticas importantes: en la historia del pensamiento económico se encuentran economistas que describen la internacionalización como la fuente de todas las desigualdades a escala mundial. Sin embargo, el tema de la ética se relaciona con el fenómeno del intercambio mucho antes de que este se vuelva internacional o "global".

El intercambio es búsqueda de satisfacción, reconocimientodelotro, necesidad de comunicación. Existen tres elementos que pueden generar conflictos entre los sujetos del intercambio mismo y requieren el establecimiento de un nivel de confianza que brota de la práctica de unas virtudes, es imprescindible actuar con lealtad, honestidad, establecer relaciones donde prime la confianza.

No obstante, hoy en día, el fenómeno de la internacionalización adquiere rasgos muy articulados, por ejemplo, ya no hay solamente comercio, sino también inversiones y nuevas modalidades de internacionalización por medio de alianzas para el intercambio de tecnología y conocimientos. La consecuencia 
es que no es posible quedarse en un nivel ideológico abstracto sin caer en la cuenta de todos los aspectos del fenómeno.

La reflexión contenida en El desafio del comercio justo en América Latina. El caso del sector artesanal nace de la idea de que el nuevo nombre de la ética en un contexto cada vez más globalizado esla palabra udesarrollow, sostenible y generado localmente. No se trata simplemente de conseguir una redistribución del valor más favorable para el productor, sino de crear más valor para todos los actores, desde la producción hasta el consumidor final: valor económico, pero también "ético". Esto no se da $\sin$ construir relaciones, alianzas "para el valor" entre personas, empresas, países, de manera que recursos "escondidos" o "desconocidos", sobre todo, el capital humano y social, puedan entrar en valorización y generar desarrollo a partir del respeto de las culturas e identidades locales.

Desde este punto de vista, se entiende el interés de abordar un tema de investigación como el del comercio justo: el movimiento nació en los países desarrollados y se propone reestablecer la justicia en los precios que se pagan a los productores del sur del mundo. Normalmente, las exportaciones que se realizan bajo esta modalidad son materias primas, como café, cacao, azúcar, fruta, cereales, etc., pero el fenómeno se ha extendido también a los productos artesanales. El libro investiga específicamente este sector porque es muy interesante desde el punto de vista del desarrollo. Los productos artesanales (textiles, confecciones, joyería, entre otros) se caracterizan por la tentativa de añadir valor a los insumos usados $y$, por lo tanto, son un modelo interesante para reducir la pobreza y mejorar la calidad profesional y humana.

En la primera parte, se profundiza el caso del Perú. El comercio justo de productos artesanales cuenta aproximadamente con el $7 \%$ de todas las exportaciones de artesanía y gracias a él se ha logrado una cierta diferenciación 
en losmercados y en los productos. otros países lacinoamericanos: Principalmente, se han realizado Argentina, Brasil, Bolivia, Chile, experiencias innovadoras en la Ecuador, México. Por otro lado, manera de organizar la "hilera» de en las conclusiones se plantea comercialización internacional: una comparación entre los casos unos gráficos sintetizan las analizadosy se describen fortalezas diferencias entre cadenas y debilidades del comercio tradicionales y del comercio justo. justo. Entre las debilidades En la artesanía tradicional, la destacan la insuficiente demanda producción de valor es muy baja, a internacional y su inestabilidad, la pesar de fortalezas como la cultura dificultad para calcular el precio local, la disponibilidad de mano "justo" por el productor, la baja de obra y materia prima de alta competitividad de las empresas calidad, y la difusión de formas involucradas en el debido asociativas. Lamentablemente, prevalecen las debilidades: baja productividad, falta de tecnologia, calidad insuficiente. En este contexto, ha nacido $y$ se ha desarrollado una notable presencia del comercio justo: la comparación con las hileras tradicionales evidencia la riqueza de modalidades de organización que, por un lado, aumentan el valor producido al inicio de la cadena $y$, por otro, fortalecen el espíritu asociativo y empresarial de los artesanos.

En la segunda parte, Internet, ampliar el mercado se analizan las, experiencias de larinoamericano, desarrollar en 
conjunto el comercio justo de productos artesanales y el turismo sostenible.

A pesar de todos los esfuerzos, el camino no es fácil y es muy probable que el comercio justo no logre todavía pasar de un rol de "testimonio" de una manera diferente de concebir las relaciones internacionales a un componente importante de los intercambios también desde el punto de vista de la cantidad exportada.

Por este motivo, la investigación ha sido extendida a todas las formas de comercio internacional que pueden conseguir el resultado de levantar el nivel ético de los intercambios sin pertenecer necesariamente al movimiento del comercio justo. Se han detectado dos aspectos interesantes: por un lado, las iniciativas de responsabilidad social empresarial $y$, por otro, la difusión de clusters o alianzas de empresas (pequeñas entre ellas, pequeñas y medianas, del norte $y$ del sur del mundo, etc.).

La investigación fue realizada en el ámbito de un proyecto financiado por el Ministerio de la Instrucción, Universidad e Investigación de Italia (MIUR), cuyo título es "Sistemas de comercialización de los productos del Tercer Mundo en los mercados desarrollados: una comparación sobre eficiencia y eficacia entre los sistemas tradicionales y alternativos", y ejecutado por una red de universidades italianas: Génova, Católica de Milán, Sapienza de Roma, Parthénope de Nápoles. Gracias al convenio de colaboración con la Universidad Católica Sedes Sapientiae (UCSS), la investigación sobre los países de América Latina fue realizada por un equipo de investigadores de la misma UCSS.

\section{Paolo Bidinost}

